UDK: 811.411 .16

\title{
ANALIZA REVITALIZACIJE HEBREJSKOG JEZIKA - NOVI JEZIK U OBEĆANOJ ZEMLJI
}

\author{
ALEKSANDAR STOJKANOVIĆ ${ }^{1}$ \\ Univerzitet u Beogradu, \\ Filološki fakultet, \\ Beograd, Srbija
}

\begin{abstract}
Rad analizira proces revitalizacije hebrejskog jezika kao često navođenog primera uspešne revitalizacije jezika čija se iskustva mogu upotrebiti u revitalizaciji drugih ugroženih ili nestalih jezika. Uspeh procesa revitalizacije hebrejskog je redak primer poklapanja političke ideologije, kolektivnog nastojanja da se jezik oživi i povoljnih socioekonomskih faktora. Hebrejski jezik je prešao iz faze „svetog jezika“ religijskih obreda u status zvaničnog jezika države i nacionalnog jezika. Rad predstavlja istorijske okolnosti, sociolingvističke faktore, kao i ekstralingvističke uticaje koji su delovali na obnovu hebrejskog jezika. Rad prikazuje proces revitalizacije kao politički i nacionalni projekat koji je uticao i na promenjenu, odnosno hibridnu prirodu hebrejskog jezika i ističe neka od iskustava koja mogu biti relevantna i za druge jezičke zajednice.

Ključne reči: hebrejski jezik, revitalizacija jezika, jezička politika, hibridnost jezika.
\end{abstract}

\section{POJAM REVITALIZACIJE JEZIKA}

Revitalizacija jezika je proces koji je u direktnoj vezi sa procesima jezičke standardizacije kroz obnavljanje i jačanje simboličke i komunikativne funkcije jezika kao simbola nacionalnog identiteta i sredstva komunikacije jedne govorne zajednice. Sam proces revitalizacije često je u direktnoj vezi i sa jezičkom politikom i planiranjem kao dugoročnim i organizovanim delovanjem na strukturu i upotrebu jezika. Spolski (Spolsky 2004: 5) jezičku politiku posmatra kao trodelnu aktivnost koja se sastoji od jezičke prakse, odnosno izbora jezika koji zajednica koristi, zatim jezičkih verovanja i ideologija o jeziku i njegovoj upotrebi i aktivnosti usmerenih na promenu jezičke prakse pomoću upravljanja jezikom i jezičkog planiranja. Proces revitalizacije je povezan sa jezičkom

1 Kontakt podaci (Email): astojkanovic@mail.com 
ideologijom govorne zajednice ali i s aktivnostima u jezičkoj praksi. Revitalizaciju definišemo kao proces koji za rezultat ima ponovno uspostavljanje jezika koji je prestao biti korišten kao jezik komunikacije u govornoj zajednici i njegovo ponovno vraćanje u upotrebu u svim sferama društva (Hinton 2003: 5). U procesu revitalizacije često je bitna uloga i delovanje državnih institucija „na različitim aspektima statusa, forme i domena upotrebe određenog jezičkog varijeteta" (Filipović 2009: 112).

Revitalizacija jezika je često u vezi sa korpusnom jezičkom politikom, koja se bavi normiranjem standardnog jezika, i statusnom jezičkom politikom koja se bavi funkcijama standardnog jezika u društvu. Slično jezičkoj politici, proces revitalizacije jezika je u vezi sa istorijskim, društvenim, ekonomskim i političkim faktorima (Filipović 2009: 103) te je revitalizaciju jezika nemoguće proučavati bez razumevanja svih ovih faktora.

Revitalizacija hebrejskog jezika se često uzima za primer najuspešnijeg i najefikasnijeg procesa revitalizacije jezika, i to u relativno kratkom vremenskom periodu i u govornoj zajednici jevrejskih doseljenika koju su karakterisali paralelna izgradnja državnog i nacionalnog identiteta i proces stvaranja nezavisne izraelske države.

Na revitalizaciju hebrejskog jezika snažno su uticali i kulturološki faktori iz Evrope, odnosno ideje 0 „svetom trojstvu“ nacionalnog jezika, nacije i teritorije (Bugarski 2005: 96). Dominantni modeli jezičkih politika u Evropi XIX veka su pojmove nacionalnog jedinstva i nacionalne države povezivali sa postojanjem nacionalnih, standardnih jezika. U evropskom nacionalističkom modelu jezičke politike koji su jevrejski doseljenici doneli sa sobom u Palestinu, jezik gradi kulturni i nacionalni identitet nacije odnosno između jezika, nacije i države postoji snažna i neraskidiva veza. U periodu revitalizacije, Jevreji nisu imali ni sopstvenu teritoriju ni svoj nacionalni jezik pa se pokret revitalizacije jezika može posmatrati i kao svojevrsno prenošenje evropskih jezičkih politika u novo okruženje. Pod snažnim uticajem shvatanja da ne može biti države bez jezika, revitalizacija hebrejskog trebalo je da obezbedi nacionalni jezik koji bi od mnoštva iseljeničkih identiteta i jezika stvorio novi hebrejski identitet i postao vezivno sredstvo za okupljanje Jevreja u nacionalnoj državi. U ovakvom poduhvatu revitalizaciju jezika pomogla je i ukupna politička ideologija cionizma kao nacionalnog jevrejskog pokreta koji je težio ponovnom uspostavljanju Izraela kao domovine Jevreja, ona ideologija koju Zukerman (Zuckermann 2009: 46) naziva „ideologijom dogodine u Jerusalimu“2.

Smit (Smith 1995: 57) govoreći o nacionalnom identitetu, definiše etničku zajednicu kao zajednicu zajedničkog porekla, zajedničkog istorijskog sećanja i mitova i zajedničke kulture povezane sa osećanjem solidarnosti i pripadnosti zajednici i određenoj teritoriji. Viland (Wieland 2004: 26) ističe da je za sve nacionalne zajednice zajedničko postojanje određenog „epicentra” oko kojeg se etnička zajednica okuplja. Bez postojanja ovakvog „epicentra“ ne može doći do kasnijeg političkog organizovanja i prelaska jedne etničke zajednice $u$ fazu nacije. On proces formiranja nacionalne zajednice sumira u jednoj formuli: „etnička grupa + faktor iks" daju „etnonaciju“ (u originalu: „ethnic group + $\mathrm{x}=$ ethnonation/community"). "Faktor iks" predstavlja

2 Radi se o molitvenim stihovima koji se izgovaraju pri kraju obredne Seder večere kojom se označava početak praznika Pashe. Ove reči su vremenom dobile, pored obrednog, i značenje duhovne i fizičke obnove jevrejskog naroda i države i, iako su bile verske odnosno obredne prirode, povezane su sa političkim idejama cionističkog pokreta. 
dodatne faktore koji su važni za formiranje nacionalnog identiteta kao što su jezik, kultura, teritorija, zajednička tradicija ili vera. Upravo je revitalizovani hebrejski jezik, pored vere, bio "faktor iks" u izgradnji države i nacionalne zajednice Jevreja u Izraelu. Jevrejski doseljenici u Palestini su bili heterogena grupa, različitih jezika ali zajedničke religije. Aktivnosti na jezičkom planiranju i revitalizaciji hebrejskog jezika su za cilj imali smanjenje jezičkih razlika, homogenizaciju doseljenika iz dijaspore i jačanje pripadnosti novoj zajednici u Palestini.

Rad će se osvrnuti na istorijske okolnosti revitalizacije hebrejskog jezika i ključne faktore revitalizacije uz poseban osvrt na vanjezičke faktore koji su revitalizaciji jezika doprineli. Analiza će obuhvatiti i ulogu političko-ekonomskih faktora na proces revitalizacije hebrejskog jezika koji su bili suštinski važni za proces nacionalne identifikacije i hebrejskog jezika kao simboličkog jezika pripadnosti novoj državi Izraelu. U radu se pokušavaju navesti i specifični razlozi koji su doveli do revitalizacije hebrejskog jezika, a koji su po svojoj prirodi atipični za sve ostale manje uspešne revitalizacije jezika (kakve su revitalizacija irskog, velškog ili maorskog jezika).

\section{HEBREJSKI ILI IZRAELSKI JEZIK?}

Hebrejski jezik uzima se za uspešan primer jezika koji je revitalizovan i oživljen nakon više od 1700 godina „kliničke smrti“ preuzimajući ulogu jezika novog društva i nove zajednice $u$ „obećanoj zemlji“, „Erec Izraelu“ (Eretz Israel). Kao najcitiraniji primer uspešne obnove jezika, lekcije naučene iz revitalizacije hebrejskog smatraju se suštinski važnim za obnovu nestalih jezika i jačanje manjinskih i ugroženih jezika. Hebrejski jezik je nakon dugog perioda „komatoznog stanja“ (Zuckermann 2006: 1) i povremene upotrebe $u$ funkciji jezika religioznih rituala ${ }^{3}$ i poezije jevrejske dijaspore ("Galut" poezije) stekao funkcije državnog i zvaničnog jezika uz znatan uticaj jezika jevrejskih doseljenika iz istočne Evrope ${ }^{4}$.

Hebrejski jezik je specifičan i zbog činjenice da je njegov nestanak bio delimičan. Nestao je u velikoj meri kao govorni jezik (mada ne i sasvim), dok je opstao kao jezik rituala i jezik religijsko-etničke identifikacije Jevreja u istočnoj Evropi te se u slučaju hebrejskog ne može govoriti o pravoj „smrti jezika", već pre o gubitku određenog domena upotrebe jezika u govornoj zajednici. Hebrejski jezik se može smatrati

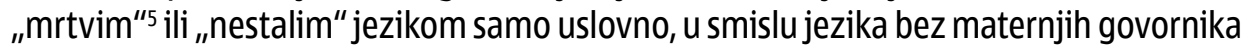
(Kaufmann 2005: 1). Posebna karakteristika obnove hebrejskog je i činjenica da je u slučaju hebrejskog cilj obnove bio da se govorne funkcije jezika daju jeziku čiji je

3 Uloga hebrejskog jezika kao obrednog, verskog jezika Jevreja u dijaspori je pozitivno uticala na kasniju obnovu hebrejskog iz dva razloga. Prvi razlog je to što je obredna uloga hebrejskog omogućila da se njegova fonološka struktura očuva i da se očuvaju glasovi koji nisu postojali u evropskim jezicima koje su Jevreji u dijaspori koristili. Drugi razlog je opstanak dobrog dela leksike hebrejskog jezika zahvaljujući razvijenoj religijskoj literaturi.

40 genezi hebrejskog jezika (ili izraelskog jezika, kako ga autor naziva) više u Zukerman (2006).

5 Smrt jednog jezika po Kristalu (Crystal 2000: 1) označava nestanak njegovih govornika odnosno jezik se može smatrati živim jedino ukoliko ima govornike. Hebrejski jezik međutim nije doživeo "smrt jezika” jer su jevrejske svete knjige Tora i Talmud bile napisane na hebrejskom te je, u različitim varijetetima, hebrejski ostao jezik religijskih rituala. 
književni status i status pisanog jezika bio već jasno definisan (Kheimets \& Epstein 2001: 124), dokje u procesu obnove jezika daleko češća situacija da se govornom jeziku daju takozvane "više" funkcije, odnosno formalne i književne funkcije jezika.

Revitalizacija hebrejskog jezika interesantna je i sa socioloških, političkih i lingvističkih aspekata, jer pokazuje znatan, ako ne i odlučujući uticaj vanjezičkih faktora na obnovu jezika. Revitalizovani hebrejski jezik predstavlja sasvim nov jezik čija je hibridnost osnovna odlika. Neki autori, poput Gilada Zukermana (2009: 46), smatraju da obnovljeni jezik treba biti nazvan izraelskim ili modernim hebrejskim jezikom zbog snažnog upliva i uticaja evropskih jezika čiji je uticaj pristigao sa talasom jevrejskih doseljenika iz evropske dijaspore. Jasno je da je hebrejski jezik tokom oživljavanja pretrpeo znatne izmene, prvenstveno u svom leksičkom fondu uvođenjem niza novih reči, ali i uvođenjem gramatičkih obrazaca iz evropskih jezika. Upravo Zukerman navodi da hebrejski pokazuje kako je „lingvistička geneza daleko složeniji proces nego što to uprošteni sistem jezičkog stabla pokazuje" (Zuckermann 2009: 41), te zaključuje da „obnovljeni jezik ne može imati samo jednog roditelja" ${ }^{\text {i }}$ da je revitalizacija jezika usko povezana sa njegovom hibridizacijom. On smatra da je obnovljeni hebrejski u stvari hibridni jezik koji naziva izraelskim, a koji je semitsko-evropski jezik ili evroazijski hibridni jezik posebnih karakteristika (Zuckermann 2009: 58). Sličan stav ima i Kaufman (Kaufmann 2005: 1) navodeći da je jezik koji je danas u upotrebi u Izraelu takozvani savremeni hebrejski jezik i da se radi o sasvim novom jeziku koji se razlikuje od svog pretka te da je ovakav rezultat logična posledica obnove jezika u svim svojim namenama za razliku od procesa očuvanja jezika ili širenja upotrebe hebrejskog kao svetog jezika predaka, koji bi bez odgovarajuće promene i prilagođavanja izgubio na upotrebljivosti i doveo u pitanje sam proces obnove jezika.

\section{MIT O BENU JEHUDI ILI KAKO SAM OBNOVITI JEZIK}

Jedan od mitova o obnovi hebrejskog jezika je i to da je reč o jeziku čiju je revitalizaciju pokrenuo jedan čovek, jevrejski doseljenik iz Rusije - Bena Jehude koji je nekonvencionalnim metodama započeo proces obnove jezika. Često nazvan i ocem modernog hebrejskog jezika (Fellman 1973), Jehuda je stekao mitski status usamljenog obnovitelja jezika čiji je rad i fanatična predanost pokrenula proces obnove jezika. Istorijski i društveni faktori pokazuju da je sam proces obnove bio decentralizovan i motivisan potrebom za građenjem društvenog i etničkog identiteta te da je uloga Bena Jehude simbolična u predstavljanju odnosa Jevreja prema novom društvu u koje su se doselili. Jedan od razloga za sistematsku obnovu jezika koje i sam Ben Jehuda navodi u člancima objavljenim u novinama i listovima jevrejske zajednice u Evropi i Africi ${ }^{7}$ jeste i taj da se pomogne jevrejskoj omladini da sačuva sopstveni identitet od procesa asimilacije u evropske kulture i zajednice u kojima su Jevreji u dijaspori živeli. Dolaskom Bena Jehude

6 Pitanje hibridne prirode hebrejskog jezika i njegove polusemitske, poluevropske prirode, razmatra Zukerman (Zuckermann 2009).

7 U članku „Važno pitanje“, Ben Jehuda je istakao potrebu za naseljavanjem Palestine da bi se između ostalog sačuvali i jezik i kultura Jevreja. „Imamo jezik kojim možemo pisati sve što želimo i imamo mogućnost da ga koristimo ako to i želimo". Više vidi Rabin (1973). 
u Palestinu 80-ih godina 19. veka, on započinje individualni rad na procesu obnove jezika i taj početak i sam rad poklapaju se sa dva velika talasa doseljavanja jevrejskih iseljenika iz Evrope ${ }^{8}$. Uglavnom se radilo o mlađim doseljenicima, zadojenim idejama evropskog nacionalizma i shvatanjima o jedinstvu jezika i nacije, odnosno države. Bili su spremni da ulože trud u izgradnju nove zajednice, nove "Obećane zemlje" na tlu Palestine koja je samim tim zahtevala i hebrejski kao nacionalni jezik i jezik kojim se raskida sa Galutom (jevrejskom dijasporom) i progonima u Evropi ${ }^{9}$. Pitanje nacionalnog jezika je od suštinske važnosti za političke i nacionalne pokrete kakav je bio i cionistički pokret kao nacionalni pokret obnove i očuvanja jevrejskog identiteta, odnosno kasnije i politički pokret uspostavljanja jevrejske države koja bi okupila sve Jevreje iz dijaspore ${ }^{10}$. $\mathrm{U}$ ovom procesu, ideje evropskih jezičkih pokreta i jezičkih politika o vezi nacije, tla i države bile su prihvaćene od strane hebrejskog pokreta kroz ideju da jedna jevrejska nacija mora imati jedan jezik koji bi bio zajednički svim jevrejskim zajednicama. Revitalizacija hebrejskog jezika tako je za cilj imala i jezičku homogenizaciju među Jevrejima, ali i otklanjanje unutrašnjih različitosti između Jevreja i svojevrstan otklon od tradicije i načina života u dijaspori. Hebrejski je, takođe, bio u stanju da izgradi osećaj grupnog i individualnog identiteta u novoj državi i simbolički označi i novi početak.

Ben Jehuda je ličnim primerom pokušao da pokaže da je revitalizacija i upotreba hebrejskog jezika moguća te je njegova porodica postala prva porodica koja je u svakodnevnoj komunikaciji koristila isključivo hebrejski jezik. Ovakva odluka bila je deo njegovog pristupa obnovi jezika koja se sastojala iz tri osnovna elementa: upotrebe jezika u kući govornika, upotrebe jezika u školi i postojanja preskriptivnih tela i propisa koji će definisati upotrebu jezika i pripremiti hebrejski jezik za upotrebu u novim okolnostima (Fellman 1973: 36) ${ }^{11}$. Novoj zemlji jevrejskog naroda trebao je i novi jezik.

8 Ove faze preseljavanja u Izrael zovu se i „alijama“. Prva je trajala od 1882. godine do 1903. godine a druga od 1904. do 1914. godine i oba talasa su činili mlađi doseljenici iz Istočne Evrope čiji su idealizam i želja za stvaranjem nove države i novog jezika bili jasno izraženi. Treća „alija“ (1919-1923) je takođe obuhvatila Jevreje iz Istočne Evrope (Rusije, Poljske i Rumunije) koji su se doselili nakon Balfurove deklaracije iz 1917. godine koja je uspostavila „nacionalni dom jevrejskog naroda” u Palestini. Četvrta „alija” (1924 -1928) je obuhvatila doseljenike iz Evrope, ali i značajan procenat jevrejskih doseljenika iz Azije i Afrike. Peta „alija“ (1929 -1939) je obuhvatila doseljenike iz centralne i Zapadne Evrope, podstaknute pojavom nacizma i fašizma u Evropi. Neki autori navode niz manjih savremenih „alija” (talasa doseljenika iz Sovjetskog Saveza 70-ih godina, arapskih država, Irana, Etiopije, Južne Amerike), kao i posebno brojnu "aliju“ masovnog doseljavanja Jevreja iz republika bivšeg Sovjetskog Saveza (1989- 2006).

9 Već u Evropi Jevreji su kroz pokret Haskala (u originalu: Haskalah, što znači „prosveta“) definisali potrebu za učenjem hebrejskog jezika, jevrejske istorije i aktivnim učešćem jevrejske zajednice u svetovnim pitanjima evropskih društava. Istovremeno su pripadnici ovog pokreta poznati pod nazivom Maskilimi (u prevodu: „prosvećeni", „učeni") u ovom periodu počeli rad na širenju svetovne književnosti i poezije pisane na hebrejskom jeziku. Haskala je kao prosvetiteljski pokret uticala na razvoj jevrejske sekularne kulture, učenje jezika sredine u kojoj Jevreji žive i ograničavanje vere na sferu privatnosti.

10 Ideja o jevrejskoj državi pojavila se 1897. godine u knjizi Teodora Hercla (Theodor Herzl), „Jevrejska država“ („Der Judenstaat"), štampanoj u Lajpcigu i Beču. Hercl je smatrao da se nepovoljan položaj Jevreja u Evropi neće promeniti te da je potrebno rešiti nacionalno pitanje, ne samo preseljavanjem u Palestinu, već $i$ sticanjem suverenih prava na teritoriju kojima bi se obezbedilo nesmetano doseljavanje u Palestinu.

11 Felman (Fellman 1973: 36) navodi sedam koraka koje je Ben Jehuda preduzeo radi uspešne revitalizacije hebrejskog jezika. Ovih sedam koraka ili oblasti na kojima je Jehuda radio obuhvataju: 1. upotrebu hebrejskog jezika u sopstvenom domu, 2. poziv jevrejskoj dijaspori da oživi i koristi hebrejski jezik, 3. stvaranje organizacija i društava koj će negovati, koristiti i promovisati hebrejski jezik, 4. učenje hebrejskog u školama, 5. štampanje novina i listova na hebrejskom, 6 . izrada rečnika hebrejskog jezika i 7. stvaranje saveta za jezik. 
Elementi ovog programa podrazumevali su i uverenje Bena Jehude da je jezik moguće obnoviti jedino ukoliko i deca usvoje i upotrebljavaju jezik tako da je Jehuda od rođenja učio svog sina i izlagao ga, uspešno, samo hebrejskom jeziku ${ }^{12}$. Praktično, primer Bena Jehude trebalo je da posluži kao simbol svim drugim doseljeničkim porodicama kako se hebrejski jezik može ponovo koristiti u svakodnevnom životu i za potrebe novog doba. Ben Jehuda je započeo i proces kreiranja novih reči za one termine za koje ograničen leksikon hebrejskog nije imao reči.

Upotrebu hebrejskog jezika u školi Ben Jehuda je podsticao i programima učenja hebrejskog jezika u školama koji su podrazumevali isključivu upotrebu hebrejskog jezika u nastavi ${ }^{13}$. U ovome je naišao i na podršku Hebrejskog udruženja učitelja koje je ideju učenja hebrejskog podstaklo odlukom iz 1892. godine da učenici od 6 . godine života uče hebrejski jezik u školama kao obavezan predmet. Hebrejski jezik je uveden u neke škole tokom 1881. godine, a već 1888. godine postao je sastavni element obrazovnog sistema te su i neki opšti predmeti predavani na hebrejskom ${ }^{14}$. Tokom 1898. godine otvorena su i prva obdaništa na hebrejskom jeziku u svim većim gradovima. Pored škola, Ben Jehuda je pokrenuo i dnevne novine na hebrejskom „Hazevi" korištenjem sistema koji je nazvao "totalni hebrejski", odnosno upotrebom samo hebrejskog jezika u pripremi i štampanju novina. Same novine trebale su poslužiti kao još jedno sredstvo širenja hebrejskog jezika, ali i učenja novih reči ili kovanica ${ }^{15}$ koje bi se u novinama pojavljivale bez objašnjenja ili fusnota sa željom da in govornici usvoje i koriste. Uporedo sa novinama, Ben Jehuda je radio i kao leksikograf na pisanju rečnika hebrejskog jezika koji je nakon njegove smrti dovršen i objavljen. Proces normativizacije jezika nastavljen je i njegovim radom na osnivanju Saveta za hebrejski jezik 1890. godine kao preskriptivnog tela koje se bavilo terminologijom, pravopisom i problemima izgovora ${ }^{16}$. Savet je imao tri zadatka (Kaufmann 2005): prikupljanje reči koje bi ušle u Rečnik hebrejskog jezika, pravljenje novih reči i standardizaciju izgovora. Savet za jezik je bio arbitar po pitanjima ispravnosti i tačnosti upotrebe jezika, ali je i sarađivao sa učiteljima i intelektualcima i prikupljao termine za nove pojmove te podsticao građane da šalju svoje predloge i ideje za leksiku. Iako je Savet prestao sa radom nakon nešto više od godine rada, njegov rad je nastavljen kroz Akademiju za jezik ${ }^{17}$ koja predstavlja najviše telo po pitanjima normativizacije hebrejskog jezika.

Pretpostaviti da je revitalizacija hebrejskog jezika rezultat truda jednog čoveka bilo bi netačno jer je celokupan cionistički pokret bio usmeren ne samo na građenje

120 biografiji, radu i stavovima Bena Jehude više u Felman (Fellman 1973).

13 Već 1882. godine takav program počeo se koristiti u osnovnoj školi u kojoj je radio i Ben Jehuda.

14 Više u Spolski (Spolsky 1996).

15 Ben Jehuda je stvorio preko 4000 novih reči koje su se zasnivale na hebrejskim korenima reči, a koje su trebale odgovoriti potrebama označavanja novih termina i pojmova.

16 Savet je 1895. godine odlučio da u izgovoru u upotrebi bude hebrejski sefardskog izgovora.

17 Akademija za hebrejski jezik predstavlja jednu od ključnih institucija jezičkog planiranja u Izraelu i imala je preskriptivnu ulogu, odnosno ulogu tela koje se brine o jezičkoj normi i „čistoti“ jezika. 0 ulozi Akademije Vilijam Čomski kaže: „....Akademija za hebrejski jezik (ranije poznata pod imenom Vaad ha-Lashon), sastavljena od izuzetnih naučnika i pisaca i podržana od izraelske vlade, budno pazi na pojavu jezičkih pogrešaka ili barbarizama koji bi mogli narušiti čistotu jezika. Akademija objavljuje listu tehničkih termina koji obuhvataju svaku granu i oblast nauke, industrije, tehnologije i sličnog: oko deset hiljada novih reči su uvedene i prihvaćene u upotrebi od uspostavljanja države Izrael." Više podataka u Čomski (Chomsky 2001). 
nacije i teritorijalno širenje već i na uspostavu hebrejskog kao nacionalnog jezika. Rad Bena Jehude tek je deo šireg pokreta u jevrejskoj dijaspori čiji je cilj bio da se izgradi etnički integrisana i kulturološki homogena nacionalna zajednica. Nakon perioda jezičke heterogenosti hebrejski je postao dominantan jezik već početkom 20 . veka i postao jezik privatne i javne sfere života u jevrejskom društvu. Usvajanje hebrejskog kao jezika komunikacije u zajednici bilo je moguće na tlu Palestine jer nije postojao zvaničan jezik tako da su već do 1918. godine više od dve trećine stanovnika u novim naseljima i kolonijama u Palestini koristili hebrejski kao jedini jezik (Izre'el 2003: 87).

\section{4. „NOVI JEZIK U NOVE MJEHOVE”}

Oživljavanje hebrejskog jezika je pred njegove zagovornike i čitavu zajednicu na tlu buduće izraelske države postavila dva veoma bitna zadatka: prvi, obnovu statusa jezika (naročito u odnosu na rivalski jidiš) i drugi, širenje korpusa jezika koji je morao odgovoriti na nove potrebe.

Današnji status hebrejskog je rezultat intervencija u statusu jezika usmerenih protiv jidiša koji je tokom prve polovine dvadesetog veka svesno i sistemski potiskivan kao pretnja hebrejskom jeziku i novom identitetu jevrejskih doseljenika. „Novi jezik“ novog identiteta i nacionalne zajednice potisnuo je jidiš kao glavni jezik evropskih Jevreja. Insistiranje na novom jeziku bilo je u uskoj vezi sa novim identitetom Jevreja u Palestini i željom da se izgradi progresivniji, aktivniji i nacionalno osvešteniji „Novi Jevrej”. Spolski (Spolsky 1996: 19), govoreći o hebrejskom i jidišu kao o dva antipoda jevrejskog identiteta, navodi:

„Sukobsajidišom nastavljenjei nakonšto se hebrejskijezikučvrstio.Jidišje shvaćen kao stalna pretnja tokom perioda imigracije i ranih dana državne samostalnosti tokom 50 -tih godina. Jidiš je bio arhetipski protivnik hebrejskog jezika. Bio je to jezik koji je bio u vezi sa dijasporom i time i odbačenim identitetom Jevrejina iz dijaspore. Bio je to jezik religioznih protivnika cionizma, grupe koja je smatrana stalnim podsetnikom na onaj odbačeni identitet. I bio je to jezik koji je pripadao identitetu koji se protivio pripadnosti teritoriji i povratku u Zion".

Iako je jidiš govorila većina doseljenika iz Evrope, jidiš je percipiran kao jezik jevrejskog egzila, jezik jevrejske dijaspore, a u odbacivanju jidiša išlo se toliko daleko da su ga rabini u Palestini nazivali treif jezikom odnosno ne-košer, nečistim jezikom koji je bio neprihvatljiv ne samo za novu jevrejsku državu već i za sam judaizam (Zuckermann 2006: 232). Iako je jidiš zadovoljavao komunikacione potrebe dijaspore i zahtevao manje intervencija i truda oko modernizacije jezika, planeri hebrejskog jezika su svesno i planski intervenisali u pravcu podrške hebrejskom jeziku. Već početkom 20. veka uspostavljena je Legija branilaca jezika koja se borila (ponekad i silom) protiv jidiša i promovisala hebrejski kao jedini prihvatljivi jezik u Izraelu. Istovremeno, Holokaust je u Evropi doveo do dramatičnog pada u broju govornika jidiša (po procenama, 85\% stradalih Jevreja u Holokaustu su bili govornici jidiša), što je imalo dalji uticaj na jačanje hebrejskog jezika kao jedinog jezika jevrejske zajednice u Izraelu. Nove talase doseljavanja u Izrael nakon Drugog svetskog rata su činili doseljenici iz Afrike, Azije, 
sa Bliskog Istoka, iz Irana i Južne Amerike, koji po definiciji nisu poznavali jidiš pa je hebrejski lako preuzeo ulogu zajedničkog jezika. Slično se desilo i sa „alijama“ iz Sovjetskog Saveza tokom sedamdesetih godina i kasnijim alijama devedesetih godina XX veka i prvih decenija XXI veka koje su činili doseljenici koji su tokom sovjetskog perioda uglavnom napustili i zaboravili jidiš te su, prvenstveno zbog ekonomskog prestiža i društvenih faktora, spremno usvojili hebrejski jezik.

Negativni stavovi prema jidišu doveli su do toga da i u samom Izraelu, u nizu kolonijalnih naseobina početkom dvadesetog veka jidiš bude odbačen $u$ korist hebrejskog jezika. Kada je osnovan Tel Aviv 1906. godine kao prvi novi grad, njegovom poveljom određen je kao grad u kojem će se koristiti isključivo hebrejski jezik (Spolsky \& Shohamy 1999: 353). Hebrejski je uspeo da se nametne tokom perioda drugog talasa doseljenika od 1906. do 1914. godine kada novi doseljenici donose i novi talas entuzijazma za učenjem hebrejskog jezika koji najbolje odslikava slogan Pokreta mladih radnika: „Jevrejska zemlja, jevrejski rad i hebrejski jezik" (Spolsky 1996: 22). Sličnu sudbinu jidiša doživeće i neki evropski jezici poput francuskog koji je bio jezik nastave u jevrejskim naseobinama pre obnove hebrejskog jezika ili nemačkog koji će biti predmet „jezičkog rata" 1913. godine nakon neuspešnog pokušaja da (nakon demonstracija pristalica hebrejskog jezika) bude uveden kao jezik nastave u visokom obrazovanju.

U ovom periodu, sve do sticanja statusa zvaničnog jezika 1921. godine, hebrejski jezik je bio samo jedan deo šireg pokreta i obnove ne samo jezika već $i$ kulture, društva i države (Harshav 1993: 21).

„Obnova jevrejske zajednice u izraelskoj državi je u velikoj meri bila određena kontrastivnim supotnostima: cionizam naspram socijalizma u dijaspori, hebrejski jezik naspram jidiša u dijaspori .....'hebrejski narod' i 'hebrejski' rad naspram iskrivljenog 'židovskog' lika."

Hebrejski jezik je iz faze jezika koji je smatran „svetim jezikom“ religijskih rituala za dvadesetak godina prerastao u zvanični jezik jevrejskih teritorija u Palestini, menjajući svoju prirodu religijsko-ritualnog jezika u ulogu jezika nacije i države. Hebrejski je iz statusa jezika čije su funkcije bile više simboličke prirode nego jezičke prerastao u jezik koji je stekao i svoju „nižu" funkciju kaojezik komunikacije. Po prvi put uistoriji jevrejskog naroda, izgrađen je jezik kao zajednički imenitelj u kulturi koja je u prošlosti prihvatila život u rasejanju i zajednički jezik jevrejskih zajednica koje su činile raznoliku i brojnu dijasporu ${ }^{18}$. Već od 1948. godine i sticanja nezavisnosti, hebrejski jezik je znalo oko 80\% stanovnika Palestine i ovim je jevrejska zajednica u Izraelu za pedesetak godina prešla put od plurilingvizma do „ideološkog monolingvizma" (Spolsky 2004:217-218) ${ }^{19}$. Borba između hebrejskog jezika i jidiša za prevlast u novoj državi simbolično je završena proglašenjem nezavisne države Izrael 1948. godine u kojoj su kao zvanični jezici priznati hebrejski i arapski jezik.

18 Koliko je koncept jednog jezika bio stran Jevrejima govori i činjenica da se početkom 20. veka govorilo više od 15 jezika povezanih sa jevrejskim zajednicama u Evropi, Aziji i Africi. Neki od njih su dugo vremena bili i rivali hebrejskom jeziku poput jidiša, ladino jezika i judeo-arapskog jezika. Revitalizacija hebrejskog jezika značila je i istovremeno potiskivanje ovih jezika.

19 Detaljni podaci o doseljavanju u Izrael mogu se naći na stranici statističkog izveštaja iz 2011. godine, po državama i periodima (vidi http://www.cbs.gov.il/reader/shnaton/templ_shnaton_e.html?num_tab=st04_04\&CYear=2011). 


\section{FAKTORI USPEŠNE REVITALIZACIJE HEBREJSKOG JEZIKA}

Uspeh obnove hebrejskog jezika je imao uticaja na koncepte obnove i revitalizacije manjinskih i ugroženih jezika, dok se hebrejski jezik smatrao svojevrsnim modelom revitalizacije koji se može slediti. Jasno je i da se radi o retkom primeru uspešne obnove i jačanju jezika koji je stekao status zvaničnog jezika i čija budućnost izgleda sigurna. Niz nelingvističkih faktora je uticao na proces obnove jezika i možemo ih grubo grupisati u pragmatične faktore i ideološke faktore. U pragmatične faktore ubrajamo činjenicu da je Izrael zemlja doseljenika i jedinstven je primer u savremenoj istoriji, te da se uglavnom radilo o doseljenicima koji su pred verskim i političkim progonima ili iz dubokog religijskog ubeđenja novi život potražili u Obećanoj zemlji. 0 Izraelu kao naciji aktivnih doseljenika spremnih na rizik i na preuzimanje odgovornosti za sopstvenu ekonomsku budućnost pišu i drugi autori (Senor \& Singer 2009: 217) navodeći da država Izrael nikada nije prestala biti zemljom doseljenika:

„Doseljenicima nije teško da krenu od nule. Po definiciji, oni su ti koji preuzimaju rizik na sebe. Nacija imigranata je nacija preduzetnika....20."

Ekonomski razvoj je zahtevao zajednički jezik baš kao i život u kibucima, zajedničkim poljoprivrednim naseljima jevrejskih doseljenika, tako da je ekonomska potreba da se nauči hebrejski snažno uticala na jačanje statusa hebrejskog jezika. Ekonomski potencijal i status hebrejskog bio je daleko izraženiji od bilo kog drugog jezika u Izraelu.

Hebrejski svoj današnji status u velikoj meri duguje i postojanju državnih institucija koje su podsticale učenje jezika u formalnom obrazovnom sistemu, ali i postojanju jezičkih škola za odrasle i radnike imigrante (u originalu „ulpan"21). Posebnu ulogu u jačanju hebrejskog imale su i oružane snage (IDF - Israeli Defence Force) kao deo izraelske države koji je od postanka imao ključnu ulogu u definisanju države i očuvanju teritorija. Oružane snage i obavezna vojna služba za sve građane Izraela su bile „najefektniji proces amalgamacije“ (Chaim 1973: 82) i kao institucija vojska je svojm pripadnicima omogućavala da razviju sopstvene veštine i društvene veze i kontakte ${ }^{22}$. Naravno da je i lanac komandovanja i službe u oružanim snagama bio isključivo na hebrejskom jeziku pa je i sama vojska organizovala jezičke programe i kurseve.

Jezička politika u izraelskoj državi je takođe pogodovala jačanju hebrejskog jer je praktično do 90-ih godina monolingvizam bio dominantan stav u učenju jezika

200 ekonomskim uspesima i privrednom razvoju Izraela više u Senor i Singer (2009).

21 Ulpani su predstavljali posebne jezičke škole za intenzivno učenje hebrejskog jezika čija je osnovna namena bila da pomognu novim doseljenicima da se što efikasnije i što brže integrišu u društveni, kulturni i ekonomski život u novoj domovini. Koncept ulpana je doživeo priličnu popularnost i kod drugih jezika koji su prošli proces revitalizacije, pa ulpani kao koncept učenja jezika za odrasle govornike postoje i na keltskom jeziku (vidi http://www.ulpan.co.uk/), i na velškom jeziku (vidi http://www.bangor.ac.uk/cio/wlpan.php. en). Više o prirodi ovih škola i sadržajima, vidi http://www.moia.gov.il/Publications/ulpan_en.pdf.

22 Izraelske oružane snage imaju sopstvene ulpan škole za regrute čiji hebrejski jezik nije na adekvatnom nivou. Istovremeno izraelske oružane snage su institucija u kojoj se društvene razlike brišu, neguje se kolektivni duh i zato je sasvim moguće da „taksisti komanduju milionerima, a da dvadesetrogodišnjaci obučavaju svoje ujake" (Senor \& Singer 2009: 55). 
u obrazovnom sistemu. Obrazovna jezička politika je tek 1996. godine zvanično prihvatila multilingvizam, definišući položaj arapskog jezika i stranih jezika (engleskog i francuskog jezika) i podstičući očuvanje manjinskih i imigrantskih jezika. Osnovni razlog dominantnog monoligvizma u izraelskom društvu bila je priroda prvih doseljenika u Izrael koji su imali izuzetno razvijen osećaj identiteta i ispunjavanja misije formiranja jevrejske države. Generacije Jevreja koji su rođeni kao Izraelci, poznati kao Sabre, predstavljali su generacije "Novog Jevrejina" koji je označavao prekid sa dotadašnjim konceptom jevrejske nacije u dijaspori. „Novi Jevrejin“ je bio rođen i odgajan u sopstvenoj zemlji i bio je rezultat posebnih kulturnih i društvenih uticaja u Izraelu koji su generaciju Jevreja rođenih u Izraelu oblikovali na drugačiji način nego što je bio slučaj sa Jevrejima u dijaspori i sa prvim doseljenicima u Izrael ${ }^{23}$. Ideali "Novog Jevrejina" su predstavljali radikalni otklon od kulture, tradicije i jezika Jevreja iz dijaspore, dok je hebrejski jezik dobio ulogu maternjeg jezika i jezika na kojem su funkcionisali svi oblici društvenog organizovanja Jevreja u Palestini.

Revitalizacija hebrejskog je postigla uspehe i zbog činjenice da hebrejski nikada nije sasvim nestao, već da je opstao u religijskoj funkciji (delimično i književnoj funkciji) te je jasno da je revitalizacija jezika daleko lakša u slučaju kada postoji korpus pisane književnosti ili dela religijskog karaktera, odnosno kada jezik očuva barem simbolične funkcije. Religijska uloga išla je pod ruku s komunikativnom ulogom koju je jezik stekao početkom revitalizacije jer je "faktor relokacije", odnosno imigracija u Izrael, uticala na zajednice jevrejskih doseljenika da se okrenu hebrejskom jeziku kao jeziku komunikacije.

Uspeh hebrejskog je redak primer poklapanja ideologije, kolektivne volje i pogodnih socijalnih i ekonomskih faktora koji su doveli do uspeha revitalizacije. Njegov uspeh pokazuje međutim da je i jezik koji proizilazi iz procesa obnove često hibridan po prirodi i da oživljavanjejezikane podrazumeva vraćanje u nekadašnjestanjejezika, većje pre dinamičan proces prilagođavanja i ekspanzije jezika kao odgovora na nove potrebe zajednice.

\section{UZOR ILI IZUZETAK?}

Pred jezičkim pokretima koji rade na očuvanju ili revitalizaciji jezika nalazi se svojevrsna dilema: da li je revitalizacija hebrejskog model koji se može replicirati ili izuzetak koji je ostao izolovani primer uspeha revitalizacije jezika?

23 "Sabra“ generacija je druga generacija Jevreja rođenih u Palestini u periodu od dvadesetih i tridesetih godina XX veka pa do šezdesetih godina XX veka. Radilo se o generaciji koja je bila suštinski važna za početni period formiranjajevrejske državei sticanja nezavisnosti. „Sabre“ su pre svega imale snažan osećaj pripadnosti kolektivu koji se ogledao u članstvu u kibucima i mošavima kao zajedničkim naseljima sa poljoprivrednom ili industrijskom proizvodnjom, učešća u programima vojne obuke mladih, kao što je Gadna, odnosno učešća u tajnim paravojnim organizacijama, kao što su bile Hagana i njena elitna formacija Palmah. „Sabra“ generacija je, za razliku od Jevreja iz dijaspore, bila pod direktnim uticajima cionističkih ideja i obrazovnog sistema u Palestini koji su je oblikovali kao generaciju „kolonista, naseljenika i branilaca“ (Almog 2000: 2). Za ovu generaciju hebrejski je bio svakodnevni usmeni i pisani jezik, odnosno maternji jezik neraskidivo povezan sa idejom nacionalne, jevrejske države. Kao ključne karakteristike Sabri neki autori (Patai 1977: 395, Zerubavel 2002: 116) navode netrpeljivost prema jevrejskoj dijaspori kao slaboj, bezličnoj i nespremnoj za očuvanje jevrejskog identiteta, snažan osećaj nacionalne pripadnosti pod uticajem cionističkih ideala, spremnost na kolektivno i lično žrtvovanje za zajednicu, spremnost na sve oblike borbe uključujući i oružanu borbu i prihvatanje hebrejskog jezika kao maternjeg jezika. 
Odgovor na ovo pitanje je da je slučaj hebrejskog i jedno i drugo. Revitalizacija hebrejskog jezika je u velikoj meri politički projekat i mnogi manjinski i ugroženi jezici nikada neće doći u položaj da postanu zvanični jezici ili jezici šire komunikacije prvenstveno zbog specifičnih političkih okolnosti nastanka Izraela, ali i činjenice da je revitalizacija jevrejskog bila deo ukupne cionističke ideologije. Nova država je značila i promenu u percepciji jevrejskog naroda koji je odbacio tradiciju i kulturu Jevreja u dijaspori, gradeći novu državu i novu naciju, gradio je i novi jezik koji je trebalo da i simbolički označi dovršetak procesa stvaranja nacionalnog identiteta. Revitalizacija hebrejskog jezika je istovremeno bila specifična jer se radilo i o rezultatu neplaniranog jezičkog planiranja koje je u inicijalnoj fazi vršeno bez podrške državnih institucija ili zvaničnh jezičkih politika. Takođe, revitalizacijom hebrejskog jezika paralelno je vršena i njegova standardizacija i modernizacija kako bi on mogao odgovoriti potrebama novonastale države. Revitalizacija hebrejskog je poseban slučaj jer se radilo 0 "oživljavanju" hebrejskog kao govornog varijeteta i jezika svakodnevne komunikacije pre nego o revitalizaciji „umrlog" jezika (Cooper 1989: 19-20) .

Ipak neke od lekcija do sada najuspešnijeg programa revitalizacije jezika mogu poslužiti i kada govorimo o jezicima koji su u sličnom položaju u kojem je hebrejski bio pre stotinak godina.

1. Obrazovni sistem je bitan, ali ne i presudan element u stvaranju mladih govornika jezika bez kojih nema prostog fizičkog opstanka jezika. Hebrejski jezik je, zahvaljujući sistemskoj podršci obrazovnih institucija i obrazovnih politika, uspeo da postane jezik formalnog obrazovanja. $U$ isto vreme, kada se govori 0 ulozi obrazovanja, ne treba zaboraviti da ciljna grupa revitalizacije nisu bila samo deca rođena u Izraelu već i odrasli govornici, doseljenici „alije“ koji su kroz ulpan škole učili, ne samo jezik, već i kulturu, tradiciju i istoriju jevrejskog naroda. Ovim je međugeneracijski prenos jezika koji je suštinski važan za revitalizaciju jezika podržannesamona nivou porodice veći ina nivou širezajednice. Takođe sistemom ulpan škola omogućeno je ne samo učenje jezika već i jevrejske tradicije, kulture i istorije, čime je proces učenja jezika praćen procesom akulturacije ${ }^{24}$. Insistiranje Bena Jehude na upotrebi hebrejskog jezika u privatnoj, porodičnoj sferi pokazalo je koliko i privatni domeni upotrebe jezika mogu biti važni u revitalizaciji.

2. Stav govornika prema jeziku i ekonomski potencijal jezika su bitni u revitalizaciji jezika jer bez pozitivnog odnosa govornika prema jeziku (ili snažnog političko-nacionalnog programa kakav je hebrejski imao kao potporu u formiranju nacionalne države) ne može doći do uspešne obnove jezika. Istovremeno, ekonomski faktori pokazuju da je revitalizacija brža i efikasnija ukoliko je revitalizovani jezik u vezi sa ekonomskim mogućnostima i prosperitetom njegovih govornika. Brzekonomski razvoj inapredak današnjeg Izraela kao nacionalne države jevrejskog naroda stare tek 60 godina, i pored stalnih ratova i političkih problema i konflikata sa susedima, imao je znatnog uticaja na učvršćivanje statusa hebrejskog jezika. Hebrejski jezik je pokazao

24 Posebnu ulogu u usvajanju jezika i akulturaciji doseljenih Jevreja imaju tzv. „centri za apsorpciju“ čija je uloga da prihvate i smeste nove doseljenike u periodu od 6 meseci (najčešće doseljenike mlađe životne dobi) uz istovremeno pružanje nastave iz hebrejskog jezika, kulture, tradicije i istorije. 
i da ekonomski status jezika i mogućnosti koje pruža govornicima mogu biti motiv za usvajanje obnovljenog jezika, dok je ekonomsko čudo Izraela omogućilo stalne talase doseljavanja („,alije“) koji su donosili nove doseljenike spremne da prihvate hebrejski jezik. Konstantan priliv doseljenika u poslednjih šezdeset godina značio je i stalan priliv novih govornika hebrejskog jezika.

3. Postojanje pisma i korpusa književnosti su elementi koji znatno olakšavaju revitalizaciju jezika kako je to i hebrejski na svom primeru pokazao. Hebrejski je imao religijsku i obrednu funkciju, kao i znatan broj pisaca u dijaspori koji su pisali religijsku poeziju na hebrejskom. Revitalizacija jezika čija su pisana forma, leksika i fonologija očuvane u određenoj meri imaju daleko veće šanse za uspeh od jezika koji su sasvim nestali, ili su im domeni upotrebe veoma ograničeni.

4. Ono što ojačajedanjezik istovremeno ubija drugijezik - odnosno revitalizacija jezika nije izolovan proces. Revitalizacija jednog jezika u zajednici može značiti slabljenje ili nestanak drugog jezika ${ }^{25}$. Na ideološkoj osnovi revitalizacija može značiti i prelazak sa multilingvizma na sistemski podržan monolingvizam. Tako je revitalizacija hebrejskog označila istovremeno eliminisanje drugih jezika koje su zajednice Jevreja koristile u dijaspori.

5. Formalno-pravni status revitalizovanogjezikaipodrška državnih tela olakšava proces revitalizacije. Proglašenje hebrejskog jezika za jedan od službenih jezika u Palestini 1922. godine ${ }^{26}$ učvrstilo je njegov status među govornicima i donelo definitivnu prevagu nad ostalim jezicima koje su jevrejski doseljenici koristili. Krajem 2014. godine u Izraelu su se pojavile političke inicijative da u okviru novog zakona o Izraelu kao nacionalnoj državi jevrejskog naroda jedini zvanični državni jezik postane samo hebrejski jezik, a arapski dobije status "specijalnog" jezika²7.

6. Revitalizovani jezik više nije isti. Konačni proizvod revitalizacije nije jezik koji je identičan svom pretku već izmenjenijezikkojije po prirodisloženiji poduticajem drugih jezika prisutnih u govornoj zajednici.Zato se govori o hibridnoj strukturi revitalizovanog jevrejskog jezika koji je tokom procesa revitalizacije bio pod uticajem drugih jezika jevrejskih zajednica i jezika jevrejskih doseljenika.

7. Odgovornost dele $\mathrm{i}$ „obnovitelji“ jezika. Loše odluke u obrazovnim politikama mogu dovesti do neuspeha u revitalizaciji. Preveliko oslanjanje samo na obrazovni sistem bez promovisanja upotrebe jezika u porodici i široj govornoj zajednici neće dovesti do potpune revitalizacije jezika već pre do stvaranja simboličke uloge jezika kao elementa tradicije ili nacionalne istorije, odnosno jezika bez stvarne komunikativne vrednosti.

25 Proces revitalizacije po pravilu nije jednosmeran već se radi o kompleksnom procesu u kojem se paralelno odvijaju i asimilacija jezičkih varijeteta u jednom revitalizovanom jeziku. Revitalizacija hebrejskog je tako značila i nestanak drugih govornih jezika jevrejskih doseljeničkh zajednica.

26 U avgustu 1922. godine, odlukom britanskih vlasti u tadašnjoj Palestini, sve zvanične odluke uprave i vlasti, kao i zvanični dokumenti lokalnih vlasti i opština bili su objavljivani i štampani na engleskom, arapskom i hebrejskom jeziku. Status hebrejskog kao zvaničnog potvrđen je i nakon sticanja nezavisnosti 1948. godine.

270 sadržaju ovog predloga zakona, trenutnim debatama o zakonu i implikacijama na status jezika, vidi http:// interviews.jadaliyya.com/pages/index/20518/israel\%E2\%80\%99s-\%E2\%80\%9Cjewish-state\%E2\%80\%9Dbill_does-it-really-change, kao i stranicu Ministarstva pravde Izraela http://index.justice.gov.il/StateIdentity/ InformationInEnglish/Documents/Basic\%20Law\%20110911\%20(1).pdf. 
Primer revitalizacije hebrejskog jezika je u velikoj meri pre izuzetak nego pravilo i oni jezici koji su danas ugroženi ili pred nestajanjem teško da će imati iste povoljne okolnosti kakve je imao hebrejski jezik. Zato se kod jezika manjih zajednica pre može govoriti o ponovnom rađanju jezika ${ }^{28}$ nego o revitalizaciji sličnoj onoj koja je zahvatila hebrejski. Kompleksan spoj političkih, kulturoloških i ekonomskih faktora stvorio je uslove za revitalizaciju hebrejskog jezika koji drugi ugroženi ili nestali jezici retko imaju. S druge strane, neka rešenja, kao što su škole hebrejskog jezika ("ulpan“), privukle su pažnju drugih jezičkih zajednica ${ }^{29}$ u pokušajima da očuvaju ili revitalizuju svoje jezike.

\section{LITERATURA}

Almog, 0. 2000. The Sabra. The Creation of the New Yew. Los Angeles: University of California Press.

Bugarski, R. 2005. Jezik i kultura. Beograd: XX Vek.

Chaim, R. 1973. Short History of the Hebrew Language. Jerusalem: Alpha Press. Chomsky, W. 2001. Hebrew: The Eternal Language. Skokie, IL: Varda Books. Cooper, R. 1989. Language planning and social change. Cambridge: CUP.

Crystal, D. 2000. Language Death. Cambridge: CUP.

Fellman, J. 1973. The Revival of a Classical Tongue. The Hague: Mouton.

Filipović, J. 2009. Moć reči. Ogledi iz kritičke sociolingvistike. Beograd: Zadužbina Andrejević. Harshav, B. 1993. Language in Time of Revolution. Berkeley: University of California Press. Hinton, L. 2003. Language revitalization. Annual Review of Applied Linguistics 23, 44-57. Hornberger, N. \& S. May. 2008. Encyclopedia of Language and Education. Volume 1: Language Policy and Political Issues in Education. New York: Springer Science.

Izre'el, S. 2003. The Emergence of Spoken Israeli Hebrew. U H. H. Benjamin (ed.) Corpus Linguistics and Modern Hebrew: Towards the Compilation of The Corpus of Spoken Israeli Hebrew (CoSIH). Tel Aviv: Tel Aviv University, 85-104. [Internet]. Dostupno na: http:// www.tau.ac.il/ izreel/publications/Emergence_Hary2003(corr).pdf [12.01.2015].

Kaufmann,J. 2005. The Revival of the Hebrew language. [Internet]. Dostupno na: http:// www.jefftk.com/final-papers/revival/revival.pdf [12.01.2015].

Kheimets, N. \& A. Epstein. 2001. Confronting the languages of statehood. Theoretical and historical analysis of the multilingual identity of the Russian Jewish intelligentsia in Israel. Language Problems and Language Planning 25 (2), 121-143.

Patai, R. 1977. The Jewish Mind. New York: Scribner.

Senor, D. \& S. Singer. 2009. Start Up Nation: The story of Israel's economic miracle. New York: Hachette Book Group.

28 Ovako neki autori definišu pojam ponovnog rađanja jezika (Skutnabb-Kangas i McCarty, citirano u Hornberger i May (2008)): „Ponovno rađanje jezika. U slučaju ugroženog jezika, osmišljeno jezičko planiranje i aktivnosti politike usmerene na: 1 . obnovu jezika, obnovu usmenih i/ili pisanih funkcija jezika koji se više ne govori i koji ima veoma slabu ili nikakvu književnu tradiciju, 2. Revitalizaciju jezika koja daje novu vitalnost ugroženom jeziku, 3. Promenu smera jezičke zamene koja daje nove generacije govornika."

29 Koncept ulpan škola pokazao se kao interesantan za govornike jezika Sami naroda u Norveškoj i njihov program obnove jezika. Više vidi http://www.cfhu.org/news/rothbery-international-school-hebrewdivision-helps-revive-an-endangered-language. 
Smith, A. 1995. Nations and Nationalism in Global Era. Cambridge, UK: Polity Press.

Spolsky, B. 1996. Conditions for language revitalization: a comparison of the cases of Hebrew and Maori. U S. Wright (ed.) Language and the State: Revitalization and Revival in Israel and Eire. Clevedon: Multilingual Matters Ltd, 5-50.

Spolsky, B. 2004. Language Policy. Cambridge: CUP.

Spolsky, B. \& E. G. Shohamy. 1999. The languages of Israel: Policy, ideology, and practice. Clevedon, UK: Multilingual Matters.

Wieland, C. 2004. Nation State by Accident: The Politicization of Ethnic Groups and the Ethnicization of Politics: Bosnia, India, Pakistan. New Delhi: Manohar publishers.

Zerubavel, Y. 2002. The "Mythological Sabra" and the Jewish Past: Trauma, Memory and Contested Identity. Israel Studies 7 (2), 115-144.

Zuckermann, G. 2006. A New Vision for Israeli Hebrew: Theoretical and practical implications of analyzing Israel's main language as a semi-engineered SemitoEuropean hybrid language. Journal of Modern Jewish Studies 5 (1), 57-71.

Zuckermann, G. 2009. Hybridity versus revivability: Multiple causation, forms and patterns. Journal of Language contact, VARIA 2, 40-67.

\section{SUMMARY}

\section{ANALYSIS OF THE REVITALIZATION OF THE HEBREW LANGUAGE - A NEW LANGUAGE IN A NEW LAND}

This article analyses the revitalization of Hebrew as an often cited example of the successful revitalization of a language, whose experience can be used in the revitalization of endangered and extinct languages. The success of Hebrew is a rare example of the overlapping of political ideology, collective striving and appropriate socio-economic factors which led to the success of language revitalization. Hebrew has gone from the phase of a "holy language" of religious rites to an official language of the Jewish communities in Palestine, changing its function from a religious role to a language of a state and a nation. The article deals with the historical circumstances, sociolinguistic factors as well as extralinguistic influences which affected the rehabilitation of the Hebrew language. It also deals with the revitalization process as the political and national project which influenced the changed, hybrid nature of Hebrew and underlines experiences which could be relevant for other language communities.

KEYWORDS: Hebrew, language revitalization, language policy, language hybridity.

(Originalni naučni rad primljen 04.11.2014; ispravljen 15.01.2015; prihvaćen 19.01.2015) 